\title{
OS CAMINHOS FILOSÓFICOS E EPISTEMOLÓGICOS QUE A EDUCAÇÃO AMBIENTAL TEM A MOSTRAR NO GT 22 DA ANPED
}

\author{
Lorena Santos da Silva ${ }^{1}$; Paula Corrêa Henning ${ }^{2}$, Virgínia Tavares Vieira ${ }^{3}$
}

\section{RESUMO}

Esta pesquisa tem por foco principal compreender como se constitui o campo de saber da Educação Ambiental, em especial os seus fundamentos filosóficos e epistemológicos, no GT22 da ANPEd (2003 - 2015). Para aporte teórico e metodológico utiliza três ferramentas analíticas presentes nas obras de Michel Foucault: problematização, documentos vistos como monumentos e suposição de que os universais não existem. Analisa 39 trabalhos, divididos entres as duas perspectivas teóricas mais recorrentes. Nessas, verificou-se a presença de três eixos discursivos: nas críticas, interdisciplinaridade, emancipação e transformação; e nas pós-críticas, discurso, poder e resistência. Evidenciou-se em ambas o caráter eminentemente político com que compreendem a Educação Ambiental, potencializando os espaços de diferenças epistemológicas e filosóficas.

Palavras-chave: Educação Ambiental; Epistemologia; ANPEd; Michel Foucault.

\section{THE PHILOSOPHICAL AND EPISTEMOLOGICAL PATHS THAT ENVIRONMENTAL EDUCATION HAS TO SHOW IN GT 22 OF ANPED}

\section{ABSTRACT}

This research has as main focus to understand how the field of knowledge of Environmental Education is constituted, especially its philosophical and epistemological foundations, in the GT22 of ANPEd (2003 - 2015). For theoretical and methodological input he uses three analytical tools present in Michel Foucault's works: problematization, documents seen as monuments and the assumption that universals do not exist. It analyzes 39 works, divided between the two most recurrent theoretical perspectives. In these, the presence of three discursive axes was verified: in the critics, interdisciplinarity, emancipation and transformation; and in post-criticism, discourse, power and resistance. The eminently political character with which they understand

\footnotetext{
1 Mestre em Educação Ambiental. Universidade Federal do Rio Grande/FURG. Capes. E-mail: lory.lorenasantos@gmail.com.

2 Doutora em Educação. Universidade Federal do Rio Grande/FURG. Capes e CNPq. E-mail: paula.c.henning@gmail.com.

3 Doutora em Educação Ambiental. Universidade Federal do Rio Grande/FURG. Capes. Email: vi violão@yahoo.com.br.
} 
Environmental Education has been evidenced in both, potentializing the spaces of epistemological and philosophical differences.

Keywords: Environmental Education; Epistemology; ANPEd, Michel Foucault.

\section{Introdução}

O presente trabalho busca apresentar os principais resultados de uma dissertação cujo objetivo pautou-se em compreender como o campo de saber da Educação Ambiental, em especial os seus fundamentos filosóficos e epistemológicos, se constitui no Grupo de Trabalho (GT 22) das reuniões científicas da Associação Nacional de Pós-Graduação e Pesquisa em Educação - ANPEd, entre os anos de 2003 a 2015.

Desde a 26a até a $37^{\text {a }}$ reunião científica tivemos um total de 154 trabalhos aprovados e publicados nos anais da ANPEd. Do total de trabalhos, mapeamos 44 artigos que se debruçam sobre os fundamentos epistemológicos e filosóficos da Educação Ambiental. Desses, 26 anunciam embasarem-se nas perspectivas críticas, 13 nas pós-críticas, 1 na teoria da complexidade, 1 na epistemologia de Fleck e 3 na filosofia hermenêutica. Com isso, têm-se cinco classificações diferentes.

Optamos trabalhar com as perspectivas teóricas mais recorrentes, investindo, por conseguinte, em trabalhos fundamentados nas perspectivas críticas e pós-críticas, com esses dois grupos contemplamos o número de 39 trabalhos aprovados. Discorremos, nesse trabalho, sobre aquilo que mais aparece, fixando especialmente em como a Educação Ambiental é tratada em ambas abordagens, dentro do mais importante evento da área educacional, os encontros da ANPEd.

Partimos dos estudos foucaultianos como fundamento metodológico e teórico para realizar a leitura desses materiais em sua superfície, naquilo que está dito. Utilizamos três ferramentas presentes nas obras de Michel Foucault (2015, 2008 e 2009): documento visto como monumento, suposição de que os universais não existem e problematização.

O olhar para o material de análise, na qualidade de monumento, é embasado pela forma com que Michel Foucault olha para a história. A Nova História não busca desvendar a suposta veracidade dos documentos, mas analisá-los, esmiuçá-los naquilo que dizem e mostram. No caso dos trabalhos 
aprovados, no GT 22 da ANPEd, tratou-se de compreender a formação discursiva da Educação Ambiental que constitui seus fundamentos epistemológicos e filosóficos, problematizando os valores políticos e sociais que se imiscuem neste campo de saber.

A intenção não foi de encontrar no corpus discursivo uma realidade objetiva, onde repouse a verdadeira e intocada face da Educação Ambiental. Este documento é tomado como objeto de estudo, "[...] devendo como tal ser decodificado em suas camadas sedimentares" (RAGO, 1993, p.30). Isso significa que o material empírico possibilitou entender parte de uma formação discursiva que coloca em funcionamento algo maior no campo ambiental. Isso tudo aponta para o vínculo estabelecido com o que Michel Foucault (2009) traçou em suas pesquisas de problematização.

Nas orientações do que é dito nas produções científicas, há discursos que falam dentro de um Regime de verdades, que vem produzindo efeitos de sentidos que polarizam as formas de se compreender a Educação Ambiental. A problematização, assim, toma como motor o pensamento que questiona e provoca os jogos de práticas discursivas que interditam ou outorgam alguns saberes. A partir das palavras do autor, é possível compreender que a problematização busca "[...] analisar, não os comportamentos, nem as ideias, não as sociedades, nem suas 'ideologias', mas as problematizações através das quais o ser se dá como podendo e devendo ser pensado, e as práticas a partir das quais essas problematizações se formam" (FOUCAULT, 2009, p. 18) [Grifos do autor]. Nesse sentido, problematizar requer a compreensão de que a verdade é uma construção humana, fabricada nas linhas das relações entre poder e saber. É possível pensar nessa correlação entre perceber os documentos enquanto monumentos à problematização a partir da suposição de "que os universais não existem [...]" (FOUCAULT, 2008, p. 5). Não são os objetos, que os trabalhos científicos estudam que examinei, mas as próprias reflexões, conceituações e explicações que efetivamente produzem a Educação Ambiental.

Tendo por base a ideia de compreender as perspectivas críticas e póscríticas na formação discursiva que compõe o campo de saber da Educação Ambiental é que nos dedicamos na próxima seção, voltando nossa atenção 
para as produções científicas do GT 22 da ANPEd que se debruçam sobre os fundamentos filosóficos e epistemológicos da Educação Ambiental.

\section{As perspectivas críticas e pós-críticas no GT 22 da ANPEd}

As produções científicas que se embasam nas perspectivas pós-críticas apresentam um outro viés de análise aos fundamentos filosóficos e epistemológicos do campo de saber da Educação Ambiental. Os conceitos se chocam entre as duas teorias educacionais produzindo defasagens que fabricam diferentes olhares para esse campo. No clivo de teorias não lidamos com uma competição, lutamos por uma mesma concepção, a politização da Educação Ambiental.

O que ambas as teorizações procuram é colocar em evidência a complexidade que constitui a Educação Ambiental, alertando para a despolitização desse campo de saber em mudanças de condutas que não cedem espaço ao pensamento. Unicamente prescrevem o que fazer e como fazer para manter um meio ambiente saudável. Ignorar tais prescrições, que ditam comportamentos corretos para uma vida sustentável, não é a questão que desacomoda a ambas teorizações, mas sim a preocupação em mostrar que no cerne das atitudes sustentáveis precisamos nos entender como sujeitos desse meio ambiente, nem destruidores, nem salvadores, mas parte integrante de um sistema de relações sociais, culturais, históricas, ecológicas e ambientais que não se findam.

Adentramos em uma problemática de cunho epistemológico e filosófico que distinguem os enunciados de uma mesma formação discursiva, lidamos como três eixos discursivos mais recorrentes em cada abordagem teórica. Nos trabalhos que assumem embasarem-se em perspectivas críticas, são acionados os conceitos de interdisciplinaridade, emancipação e transformação, e em perspectivas pós-críticas, discurso, poder e resistência. É partir desses eixos enunciativos que realizamos nossas análises. Primeiramente trataremos de mostrar a potência de cada um desses conceitos nos trabalhos selecionados.

A aproximação das condições interdisciplinares e transdisciplinares da Educação Ambiental são expostas nas pesquisas científicas como parte 
eminente de um projeto político e educacional, pautado na fomentação da aproximação de diferentes áreas do conhecimento científico com saberes locais e tradicionais. Vemos essa conjuntura no excerto do material empírico.

\begin{abstract}
Em síntese, partindo da perspectiva interdisciplinar, seja na produção de conhecimento e/ou no processo de ensinoaprendizagem, transitando entre saberes científicos, populares e tradicionais, a EA Crítica busca mecanismos para que o indivíduo e a coletividade assumam uma postura reflexiva frente à problemática ambiental e busquem elementos para a consolidação de uma sociedade sustentável (SILVA, 2007, p.3). [Grifo nosso]
\end{abstract}

Por via da análise dos trabalhos selecionados foi possível concluir que, a interdisciplinaridade se faz presente na esfera pedagógica, mas não se resume a essa, perpetua-se enquanto questão epistemológica, política e cultural. As noções extraídas do material empírico sobre a interdisciplinaridade trazem as marcas de um modo de pensar muito particular de um posicionamento com vistas às perspectivas críticas. Nesse sentido:

A EA (crítica) pode ser compreendida como uma filosofia da educação que busca reorientar as premissas do pensar e do agir humano, na perspectiva de transformação das situações concretas e limitantes de melhores condições de vida dos sujeitos - o que implica mudança cultural e social (TORRES, FERRARI \& MAESTRELLI, 2014, p. 14). [Acréscimo dos autores].

Nesta esteira enunciativa, verificamos a potência que a emancipação dos sujeitos é tomada nos trabalhos selecionados. Nesses o conceito de emancipação apresenta-se junto a um objetivo educativo que confronta o poder hegemônico, singularizado pelos meios de produção capitalista. Na busca por emancipá-los prepondera a ideia de que esses precisam perceber-se e constituir-se como cidadãos politicamente participativos e conscientes de sua condição para que seja possível uma mudança das relações sociais, ambientais, econômicas, educativas e políticas. Vejamos 0 excerto selecionado do corpus empírico:

O que a Educação Ambiental propõe é uma teoria comprometida com a emancipação dos sujeitos, com a transformação da realidade socioambiental. A teoria é importante porque nos ajuda a compreender a prática, não porque seja superior à prática como durante muitos anos nos fez acreditar a ciência moderna (TRISTÃO, 2004, p.12). [Grifo nosso].

Nos trabalhos analisados, a polarização entre teoria e prática, é 
assumida a partir da prerrogativa de que se faz necessário, através da práxis, articulá-las para que a emancipação dos sujeitos oprimidos aconteça. Lidamos com uma noção de sujeito que no caminho de uma educação crítica consegue libertar-se das relações de poder. O poder, assim, é tomado como algo pertencente a uma minoria, algo que oprime e aliena.

O modelo de produção capitalista é entendido como principal responsável pela condição de separação entre ser humano e natureza. Tornar visível a ideologia reproduzida por esse modo de produção, exige o esclarecimento e o desvelamento das relações ideologizadas. Voltamos a importância do esclarecimento das consciências e da articulação entre teoria e prática, para que seja possível emancipar-se e perceber-se enquanto parte da natureza, tendo assim posturas ecológicas e políticas que vão de encontro ao sistema econômico vigente, possibilitando a efetivação do processo de transformação de uma sociedade em crise para uma sustentável. Permeando o último eixo enunciativo - Transformação - é que trazemos o excerto do material empírico.

Na perspectiva de uma Educação Ambiental crítica, torna-se fundamental discutir as várias concepções de desenvolvimento econômico em disputa $e$ as matrizes discursivas que as fundamentam (ideologias, valores, comportamentos), tendo em vista a superação da alienação homem-natureza e a construção de um modelo alternativo de desenvolvimento contrahegemônico, apoiado na "sustentabilidade democrática" e na superação da desigualdade e da exclusão social, que se reflita nas concepções e práticas educacionais (DELUIZ \& NOVICKI, 2004, p. 12). [Acréscimo dos autores] [Grifo nosso].

Distinguimos a Educação Ambiental como crítica preenchendo-a de sentido político; como uma ação política de transformação das relações dos homens entre si e deles com o ambiente, no sentido histórico. Para subsidiar este tipo de prática acreditamos na contribuição do referencial baseado na Teoria Crítica, com forte influência teórico-prática no pensamento marxista; ou seja, no materialismo histórico dialético. O método dialético busca a construção de uma visão integradora de ciência e filosofia, informando uma atuação transformadora das relações sociais (OLIVEIRA, 2011, p.5). [Grifo nosso].

Os excertos demonstram que a ideia de transformação dos meios de produção foi sendo articulada a outras transformações, tais como: Transformação das relações entre ser humano e natureza, das desigualdades sociais, da crise ambiental, da abordagem epistemológica, filosófica e pedagógica da educação, assim como, dos valores éticos e morais. 
Transformações essas, igualmente vistas como necessárias a uma Educação Ambiental crítica. Tudo isso, sem desconsiderar a indispensabilidade de transformar o sistema econômico.

Essa articulação não supõe que as enunciações referentes à transformação tenham perdido seu valor, aliás, justo o contrário! Como nos ensinou Foucault (2015), as formações discursivas não são estanques, ou seja, estão em conformidade com outros sistemas de formação que exigem a presença de outros enunciados para dar conta de novas problemáticas que vêm sendo aderidas ao campo de saber da Educação Ambiental.

De um modo geral, entre os três eixos de análise - interdisciplinaridade, emancipação e transformação - há uma confluência enunciativa em diferentes temas dos trabalhos selecionados, quais sejam: institucionalização escolar, risco ambiental, aproximações com Paulo Freire, alfabetização de jovens e adultos em uma cooperativa de resíduos sólidos, filmes, práxis pedagógica, natureza, mudanças climáticas. Tais temas são tomados como escopo dos estudos, trazendo conceituações que dão corpo ao que tem se entendido por Educação Ambiental nas linhas teóricas críticas.

A coexistência de posições heterogêneas no campo da Educação Ambiental é um caminho possível para que esse campo de saber se fortaleça, enquanto contestador e problematizador das formas de nos relacionarmos conosco, com os outros e com o meio ambiente. As problematizações políticas que são acionadas em diferentes trabalhos do GT 22, com diferentes modos de olhar os problemas ambientais, as relações humano-natureza me parecem extremamente necessárias para potencializar o campo e subverter os modos enfraquecidos com que a Educação Ambiental é hoje posicionada em diferentes políticas públicas, sejam nacionais ou internacionais. É pensado na potencialidade criativa do diferente que passamos a apresentar as estratégias analíticas e conceituais dos três eixos enunciativos mais recorrentes - discurso, poder e resistência - entre os trabalhos fundamentados em perspectivas póscríticas.

As pesquisas se debruçam sobre o conceito de discurso embasado no pensamento foucaultiano, recusando a busca pela veracidade obscurecida pelo discurso. O discurso é analisado naquilo que está dito, detém-se ao nível da existência das palavras compreendendo que não há uma correlação direta 
entre as palavras e as coisas. Michel Foucault (2015, p. 59) afirma que com a Análise do discurso:

[...] gostaria de mostrar que os "discursos", tais como podemos ouvilos, tais como podemos lê-los sob a forma de texto, não são, como se poderia esperar, um puro e simples entrecruzamento de coisas e de palavras: trama obscura das coisas, cadeia manifesta, visível e colorida das palavras; gostaria de mostrar que o discurso não é uma estreita superfície de contato, ou de confronto, entre uma realidade e uma língua, o intrincamento entre um léxico e uma experiência; gostaria de mostrar, por meio de exemplos precisos, que, analisando os próprios discursos, vemos se desfazerem os laços aparentemente tão fortes entre as palavras e as coisas, e destacar-se um conjunto de regras, próprias da prática discursiva.

O campo de saber da Educação Ambiental é formado de discursos presentes em diferentes artefatos que incidem na subjetivação dos sujeitos em diferentes momentos da vida. Não se trata de entender que a Educação Ambiental emerge da conscientização dos sujeitos sobre os desmatamentos, o derretimento das geleiras, as catástrofes ambientais, a poluição, o aquecimento global, a extinção de espécies, enfim, mas de olhar para os discursos que se produzem a partir dessas materialidades como fabricações que alertam para a necessidade de pensar formas de existência mais sustentáveis, que garantam a sobrevivência do planeta. A ênfase do trabalho exemplificado abaixo está justamente nessa visão:

Para o bem ou para o mal, tais discursos reverberam cotidianamente na mídia e em outros espaços em que a vida se coloca como questão central para continuidade do futuro do planeta. Com isso, a Educação Ambiental toma força e vem se constituindo num campo de visibilidades diante da preocupante devastação do meio ambiente. [...] $O$ que queremos colocar em evidência, no entanto, são os discursos da periculosidade e a política do medo que muitas vezes a mídia ajuda a propagar, intensificando uma atitude individualista, tanto de culpabilização pelo problema (Você é o culpado!), quanto de redenção solitária frente à crise (Salve sua própria pele enquanto há tempo!) (RATTO \& HENNING, 2012, p. 6). [Grifo nosso]

O que os autores colocam em questão no excerto acima não é a materialidade da qual o discurso se debruça. A ênfase está na forma com que a crise ambiental é produzida na mídia, acionando práticas individualistas perante as questões ambientais. A produção do discurso que reafirma o perigo eminente das catástrofes ambientais e do próprio fim do Planeta são muito mais do que conjunto de palavras, são saberes legitimados para evidenciar a indispensabilidade de mudança em nosso comportamento. 
O foco dos trabalhos, que se amparam na noção foucaultiana de discurso, é mapear, compreender e discutir as formas com que vão sendo fabricados modos de entender nossa relação com o meio ambiente, seus desdobramentos, na constituição de saberes outorgados como necessários, e a relação desses no sistema de captura dos sujeitos no limiar dos discursos voltados às questões ambientais. Dito isso, é verossímil afirmar a relação que o corpus empírico toma entre discurso e poder. Tal relação pode ser analisada nas discussões tecidas no excerto abaixo:

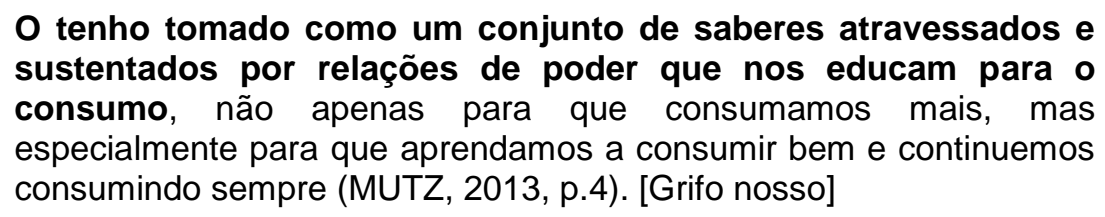

Nos trabalhos mapeados, as relações de poder são entendidas como fundamentais na fabricação dos ditos ambientais, na seleção dos saberes, na produção da necessidade de educar-se ambientalmente. A legitimidade científica torna-se uma condição importante para alertar sobre os reveses que ocorrem no meio ambiente e afetam a todos os seres vivos que habitam esse Planeta. No excerto do corpus empírico abaixo é possível perceber a potência das relações de poder na emergência da Educação Ambiental.

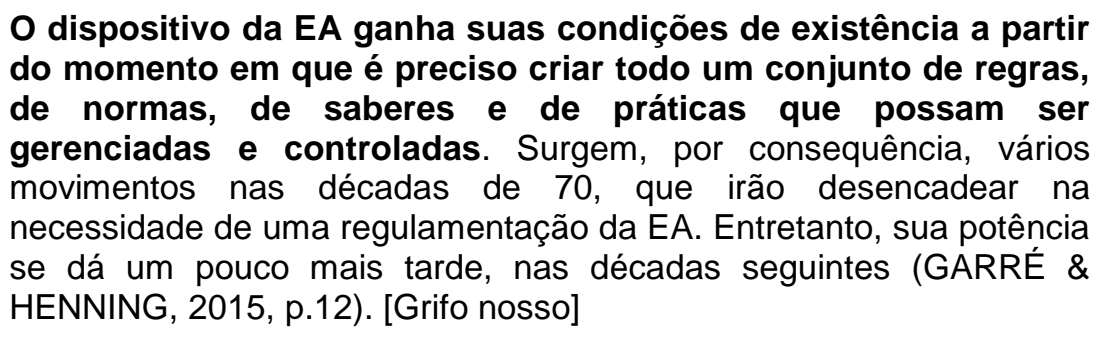

Para além do julgamento do bem e do mal, as relações de poder são vistas também por sua positividade, produzem saberes, verdades e nossa vida em sociedade. Sua fluidez está em todo o tecido social, nossa liberdade está atrelada às relações de poder. "Isso significa que, nas relações de poder, há necessariamente possibilidade de resistência, pois se não houvesse possibilidade de resistência - de resistência violenta, de fuga, de subterfúgios, de estratégias que invertam a situação -, não haveria de forma alguma relações de poder" (FOUCAULT, 2017, p. 270). Não há poder, se não houver 
resistência, ao ser retirado a liberdade de resistir estamos lidando com uma outra coisa que não o poder.

A resistência apresenta-se no corpus discursivo como uma possibilidade de respiro, de fissura perante aos discursos que estão disseminados em espaços formais, informais e não formais. Tal conceito, no corpus empírico, se concentra em mostrar outras possibilidades de pensar a Educação Ambiental e as formas de nos relacionarmos com o meio ambiente, colocando em suspenso verdades que se destinam às questões ambientais e educacionais.

Para esmiuçar o conceito de resistência, foi preciso separar os trabalhos em dois grupos. O primeiro refere-se as pesquisas que utilizam tal conceito a partir do exercício do pensamento sobre nossa relação com o meio ambiente circulante em diferentes espaços e artefatos. O segundo grupo versa especialmente sobre as possibilidades educacionais que criem suspeitas, insurreições e estratégias de resistência. Passemos, inicialmente, ao primeiro grupo.

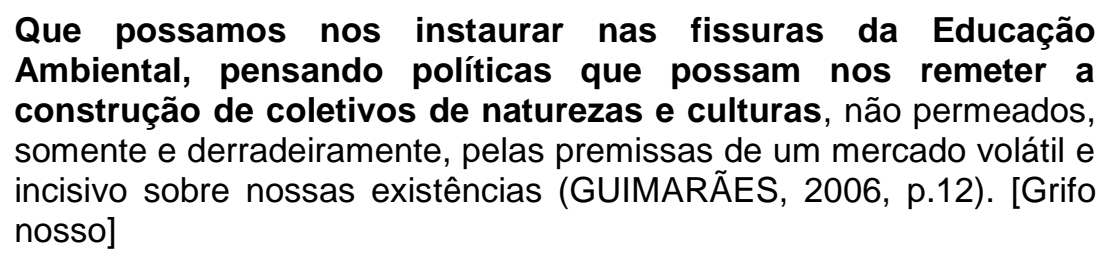

A intenção dos trabalhos desse primeiro grupo paira sobre o desejo de mostrar a exterioridade de discursos que constituem a Educação Ambiental. Não se trata de uma derradeira necessidade de substituí-los, mas de tensionálos a ponto de possibilitar a criação de fissuras, de problemas, de interrogações que nos movimente para a problematização de nossas condutas. Para Michel Foucault (2008, p. 260 a) "[...] por mais que essas revoltas de conduta possam ser específicas em sua forma e em seu objetivo, nunca são autônomas, nunca permanecem autônomas, qualquer que seja o caráter decifrável de sua especificidade". Dessa forma, não se trata de desconsiderar a relevância das condutas sustentáveis, mas de provocar-se sobre os motivos que nos movem a adotá-las.

O segundo grupo vê na Educação Ambiental e em suas práticas pedagógicas a possibilidade de desafiar uma visão unitária e totalizante, convidando a pensar a educação como ato criativo e contestador. Para discutir o ato de resistência no pensar e agir pedagógico da Educação Ambiental, 
trouxe dois excertos que traduzem as premissas desse segundo grupo:

\begin{abstract}
Deixar-se ser afetado por saberes que colocam em cheque todo nosso edifício conceitual para permitir um devir criativo em nossas ações. Permitir um ensinar que não se baseia em ações prédefinidas, preparadas, pois quando se age preparado (para algo que nunca se sabe o que será) se "age" pela defensiva, pela reatividade, deixa-se passar uma linha de fuga que poderia dar origem a um momento criativo, transformador. (PALHARINI, 2005, p.16). [Grifo nosso]
\end{abstract}

A Educação Ambiental, nesta perspectiva, busca envolver-se com práticas que construam relações de cultivo do pensamento, de si e dos outros. Nisso, pensamento e prática, saber e poder, problematização e filosofia caminham juntos. A negação da disciplinarização dos saberes e corpos na educação não coaduna com os movimentos de resistência no contexto educacional, é preciso reconhecê-las para que seja possível pensar outras formas de constituir-se sujeito. É isso que Michel Foucault (2013) nos ensina em seu livro "Vigiar e Punir", após toda uma análise minuciosa das regras, discursos e instituições que fabricam o sujeito disciplinar o filósofo nos alerta para o compromisso de "[...] ouvir o ronco surdo da batalha" (FOUCAULT, 2013, p. 291).

A recorrência dos conceitos de discurso, poder e resistência, nesses 13 trabalhos, evidenciam a preocupação em problematizar o esvaziamento da Educação Ambiental cada vez mais premente em âmbito nacional e internacional. É preciso "[...] sacudir a quietude com a qual as aceitamos" (FOUCAULT, 2015, p. 31), colocando sob suspeita qualquer universalidade que afirme o caminho unívoco, a conduta correta ou a linha de pensamento verdadeira.

Extrai-se das análises realizadas que as diferenças entre ambas teorizações produzem a multiplicidade e não o distanciamento. Estabelecer uma forma linear e universal de compreender a Educação Ambiental deve ser, no mínimo, estranhada por nós pesquisadores e pesquisadoras desse campo de saber. A universalidade enfraquece a possibilidade da criação e do pensamento múltiplo. No instante em que se decide negar uma teorização, nega-se a potência de sua ação política e de problematização das verdades que ditam as condutas mais corretas, as análises mais verdadeiras ou mesmo a posição mais política. Na palestra realizada no IX Encontros e Diálogos com 
a Educação Ambiental, a Profa. Dra. Paula Henning (2017) nos dá indícios de que:

\begin{abstract}
Dar vasão à vida e as múltiplas possibilidades de experimentá-la é o que se pode fazer em nossa luta diária contra as prescrições que historicamente foram fabricando a Educação Ambiental. Expandir as forças, encontrar frestas de ar parece ser uma possibilidade para nós que nos encontramos desencaixados na colonização do pensamento pedagógico, na colonização de uma racionalização pautada na sustentabilidade.
\end{abstract}

Distanciar-se das prescrições, apresenta-se como uma possibilidade de luta a qual a autora nos chama a atenção. Suspeitar do aconchego que a certeza nos traz é aceitar o abismo da incerteza, e isso não é tarefa fácil! Nos formamos sujeitos no solo epistêmico moderno, em alguma medida queremos verdades, queremos as certezas, mas "O que importa é assumir essa atitude de suspender o consolador estado das certezas para, no lugar delas, construir e pensar fatos, coisas, dados, situações inquietantes de nosso tempo [...]" (FISCHER, 2007, p. 61). Problematizar se trata de um constante exercício de pensar sobre o pensamento amparando-se no entendimento de que na medida em que as limitações são colocadas é que podemos procurar produzir fissuras.

\title{
Considerações Finais
}

O que propomos foi sobretudo pensar sobre o que é dito entre educadores e pesquisadores ambientais, dentro das reuniões científicas da ANPEd, que se filiam a correntes teóricas recorrentes no campo de saber da Educação Ambiental. Partimos do entendimento de que os diferentes conjuntos de enunciações dão conta de fabricar, de maneira diversa discursos que não tem, estritamente, por obrigatoriedade abrigar apenas um único olhar, mas também visões diversas, disparatadas e dispersas.

Não há de um lado uma boa teoria e de outro uma má, ou uma concepção que age e outra que pensa, o que percebemos são formas díspares de estranhar os modos com que a Educação Ambiental é acionada, na tentativa de pensar outros cenários para esse campo de saber. Mediante essa postura é verossímil compreender que:

[...] não há um tempo para a crítica e um tempo para a transformação. Não há os que fazem a crítica e os que transformam, os que estão encerrados em uma radicalidade inacessível e aqueles que são obrigados a fazer concessões necessárias ao real. Na realidade, eu 
acredito que o trabalho de transformação profunda pode apenas ser feita ao ar livre e sempre excitado por uma crítica permanente (FOUCAULT, 2010, p. 357).

Com o conjunto de análises realizadas vimos abordagens teóricas e metodológicas distintas que possuem bases filosóficas e epistemológicas divergentes. Todavia a crítica e o desejo de mudança fazem-se presente. A inquietude mostrou-se recorrente entre as produções científicas voltadas à Educação Ambiental.

Resta evidente que tais divergências teóricas, filosóficas e epistemológicas são o que fabricam o campo de saber da Educação Ambiental. Neste sentido é que o exercício de pensar sobre o que está dito se torna tão relevante, para que não recaiamos em discussões morais sobre qual posição ou qual verdade deve predominar. São os jogos de diferenças que potencializam e que dão visibilidade para o campo da Educação Ambiental. Foi especialmente isso que buscamos mostrar, através de tensionamentos e de provocações.

\section{Referências}

DELUIZ, Neise; NOVICKI, Victor. Trabalho, meio ambiente e desenvolvimento sustentável: Implicações para uma proposta crítica de educação ambiental. 2004. In: $\mathbf{2 7}^{\mathbf{a}}$ Reunião Científica da Associação Nacional de Pós-Graduação e Pesquisa em Educação. Disponível em: http://27reuniao.anped.org.br/gt22/t2210.pdf. Acesso em: 28 maio 2018.

FISCHER, Rosa Maria Bueno. Verdades em suspenso: Foucault e os perigos a enfretar. In: COSTA, Maria Vorraber (org.). Caminhos Investigativos II: outros modos de pensar e fazer pesquisa em educação. 2 ed. Rio de Janeiro: Lamparina editora, 2007.

FOUCAULT, Michel. O nascimento da biopolítica: curso dado no Collège de France (1978-1979). São Paulo: Martins Fontes, 2008.

FOUCAULT, Michel. Segurança, território e população: curso dado no Collège de France (1977-1978). São Paulo: Martins Fontes, 2008 a.

FOUCAULT, Michel. História da Sexualidade 2: o uso dos prazeres. 13 ed. Rio de Janeiro: Edições Graal, 2009.

FOUCAULT, Michel. Ditos \& Escritos VI: Repensar a Política. Rio de Janeiro: Forense Universitária, 2010.

FOUCAULT, Michel. Vigiar e punir: nascimento da prisão. 41 ed. Petrópolis: Vozes, 2013. 
FOUCAULT, Michel. Arqueologia do Saber. $8^{\mathrm{a}}$. Ed. Rio de Janeiro: Forense Universitária, 2015.

FOUCAULT, Michel. Ditos \& Escritos V: Ética, sexualidade, política. Rio de Janeiro: Forense Universitária, 2017.

GARRÉ, Bárbara Hees; HENNING, Paula Corrêa. Urgência histórica do dispositivo da educação ambiental: mapeando algumas condições de possibilidade para o aparecimento do campo de saber ambiental. 2015. In: 37 ${ }^{\mathbf{a}}$ Reunião Científica da Associação Nacional de Pós-Graduação e Pesquisa em Educação. Disponível em: http://37reuniao.anped.org.br/wpcontent/uploads/2015/02/Trabalho-GT22-3945.pdf.

Acesso em: 24 maio 2018.

GUIMARÃES, Leandro Belinaso. A importância da história e da cultura nas leituras da natureza. 2006. In: 29 ${ }^{a}$ Reunião Científica da Associação Nacional de PósGraduação e Pesquisa em Educação. Disponível em: http://29reuniao.anped.org.br/trabalhos/trabalho/GT22-1726--Int.pdf. Acesso em: 20 maio 2018.

HENNING, Paula Corrêa. Verdades Educacionais no Brasil e na Espanha: tensionamentos ambientais sob análise. Rio Grande: Universidade Federal do Rio Grande. 2017. (Comunicação oral)

MUTZ, Andresa Silva da Costa. A educação ambiental e o discurso do consumo consciente: uma análise sobre os modos como se produzem sujeitos consumidores nas pedagogias culturais contemporâneas. 2013. In: 36 ${ }^{\mathbf{a}}$ Reunião Científica da Associação Nacional de Pós-Graduação e Pesquisa em Educação. Disponível em: http://36reuniao.anped.org.br/pdfs_trabalhos_aprovados/gt22_trabalhos_pdfs/gt22_278 4 texto.pdf. Acesso em: 30 maio 2018.

OLIVEIRA, Aline Lima de. Contribuições da participação à práxis política e emancipatória em Educação Ambiental. 2011. In: 34 ${ }^{\mathbf{a}}$ Reunião Científica da Associação Nacional de Pós-Graduação e Pesquisa em Educação. Disponível em: http://34reuniao.anped.org.br/images/trabalhos/GT22/GT22-547\%20int.pdf. Acesso em: 30 maio 2018.

PALHARINI, Luciana. A educação ambiental enquanto acontecimento. 2005. In: 28 ${ }^{\mathbf{a}}$ Reunião Científica da Associação Nacional de Pós-Graduação e Pesquisa em Educação. Disponível em: http://28reuniao.anped.org.br/textos/gt22/gt221587int.doc. Acesso em: 27 maio 2018.

RAGO, Margareth. As marcas da pantera. Foucault para historiadores. Resgate, vol.4, n.5, p. 22-32. 1993. Disponível em http://www.cmu.unicamp.br/seer/index.php/resgate/article/view/55. Acesso em: 17 maio 2018.

RATTO, Cleber Gibbon; HENNING, Paula Corrêa. Urgências sócio-ambientais contemporâneas: por uma ética do cuidado planetário ante a política do medo. 2012. In: 35 Reunião Científica da Associação Nacional de Pós-Graduação e Pesquisa em Educação. 
http://35reuniao.anped.org.br/images/stories/trabalhos/GT22\%20Trabalhos/GT221599_int.pdf. Acesso em: 27 maio 2018.

SILVA, Rosana Louro Ferreira. O meio ambiente por trás da tela: concepções de educação ambiental dos filmes da tv escola. 2007. In: 30 ${ }^{\mathbf{a}}$ Reunião Científica da Associação Nacional de Pós-Graduação e Pesquisa em Educação. Disponível em: http://30reuniao.anped.org.br/trabalhos/GT22-3678--Int.pdf. Acesso em: 23 maio 2018.

TORRES, Juliana Rezende; FERRARI, Nadir; MAESTRELLI, Sylvia Regina Pedrosa. Educação Ambiental crítico-transformadora no contexto escolar: teoria e prática freireana. In: LOUREIRO, Carlos Frederico Bernardo; TORRES, Juliana Rezende (orgs.). Educação ambiental: dialogando com Paulo Freire. São Paulo: Cortez, 2014.

TRISTÃO, Martha. Os contextos da educação ambiental no cotidiano: racionalidades da/na escola. 2004. In: 27 ${ }^{a}$ Reunião Científica da Associação Nacional de PósGraduação e Pesquisa em Educação. Disponível em: http://27reuniao.anped.org.br/gt22/t229.pdf. Acesso em: 23 maio 2018. 